\title{
Evaluation and Management Services in Interventional Pain Practice: Doing it right!
}

\author{
Laxmaiah Manchikanti, MD
}

Proper coding and documentation for evaluation and management services continuously and progressively are becoming not only complicated, but also confusing. Although medical evaluation of patients has been a fact of life since the beginnings of medical history, medicine has been substantially influenced by federal regulations since the enactment of Medicare. Physicians' fear of being prosecuted is increasing. This is reinforced by actions of the federal government in multiple cases with sky-high penalties and by the Office of the Inspector General's target of 600,000 physicians in practice in its work plan for the new millennium.

Evaluation and management services utilization, medical necessity, and appropriate documentation for level and complexity of service are extremely important components of evaluation and management services. Similarly, differentiating between a consult versus a visit is also crucial to avoid upcoding, or in a worst-case scenario, downcoding. While the history is the same for all types of visits except for the complexity for each level, four types of physical examination are available, either in a general multisystem examination or a single-system examination. However, the complexity of medical decision making is the essential factor in deciding to which level the evaluation and management belong.

This review will discuss various aspects of evaluation and management guidelines in interventional practice and also guide the physician in performing these evaluations in an appropriate manner with proper documentation, thus avoiding the pitfalls of fraud and abuse.

Keywords: Evaluation and management services, interventional pain practice, history, physical examination, medical decision making
Over the last few years there has been significant confusion over the proper coding and documentation for evaluation and management services in general and interventional pain management in particular. The confusion has been made worse by numerous articles published in a multitude of advisory publications and misguided advice by well-meaning consultants (1). Interventional pain physicians have learned basic evaluation of patients presenting with pain based on their speciality training. While modern training programs are now introducing residents and fellows to the intricacies of evaluation and management services and federal regulations, this has not always been the case. In a 1999 tutorial in Pain Digest entitled "History Taking - Examination and Management of Low Back Pain," the authors provided techniques of history taking, physical examination, psychological assessment,

From Pain Management Center of Paducah, Paducah, Kentucky. Dr. Manchikanti is medical director of Pain Management Center of Paducah. Address correspondence: Laxmaiah Manchikanti, M.D., 2831 Lone Oak Road, Paducah, Kentucky 42003. Email: drm@ apex.net imaging in low back pain, special neurological testing, pain-producing structures in low back pain, diagnosis of pain syndromes, and rationale for management and available modalities (2). Similarly, multiple textbooks of pain management, physiatry, and neurology have described the evaluation of pain patients (3-7). While these publications were written by well-meaning, well-read academicians, it is unfortunate that none of them meets evaluation and management documentation criteria according to the level of service established by the Health Care Financing Administration (HCFA).

\section{HISTORICAL CONSIDERATIONS}

The medical evaluation of patients has been a fact of life since the beginnings of medical history. Over the years, advances in medicine, increasing knowledge, and understanding of the physiologic concepts of pain have dramatically improved the evaluation process. While medicine was always influenced by federal regulations, the influence of laws and regulations has become much more intrusive since the enactment of Medicare. In the evolution of numerous regulations governing the practice of 


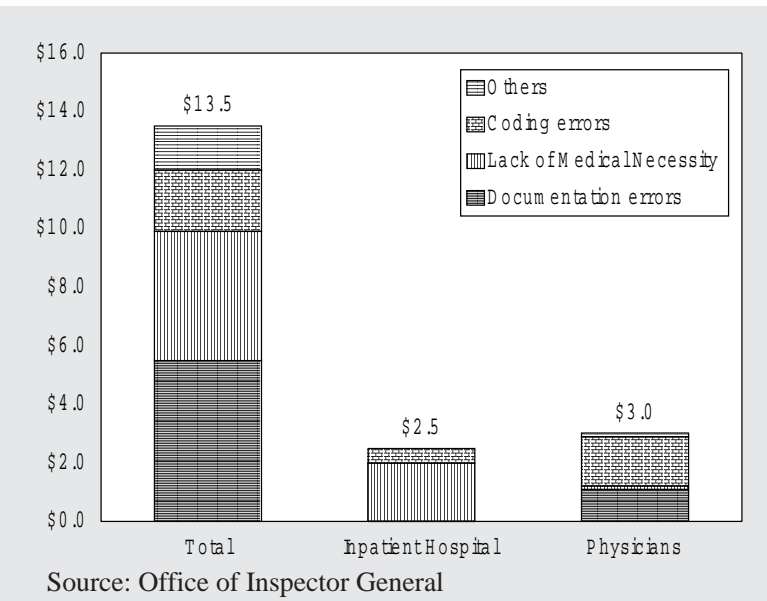

Fig 1. Medicare overpayments of improper billing for 1999

medicine by HCFA, implementation of evaluation and management guidelines started in the 1990s. The latest guidelines by HCFA were developed in 1997 . The new proposed guidelines are awaiting pilot testing and are expected to be released in the later part of this year or early next year. Consequently, HCFA has permitted providers to use either the 1997 or 1995 versions of the guidelines (8).

\section{APPROPRIATE DOCUMENTATION}

Never in U.S. history has there been such an emphasis placed on the description and definition of what the physician does for and to the patient (9). Compliance with laws and regulations encompassing documentation, medical records, coding, billing, collections, contracts, auditing, and other areas is of crucial importance in the practice of interventional pain medicine. The Balanced Budget Act of 1997; The Kennedy-Kassebaum Reform Bill of 1996; The Budget Reconciliation Act of 1997; the National Correct

\section{Table 1. Consequences of inaccurate coding} and billing in the order of importance

\begin{tabular}{ll}
\hline - Prison & - Exclusion \\
- Sanctions & - Fines \\
- False claims & - Denied claims \\
- Trigger a review & - Returned claims \\
- Suspended claims & - Down coding \\
\hline
\end{tabular}

Table 2. Exclusions of medical providers

\begin{tabular}{lcc}
\hline Physician Specialty & $\begin{array}{c}\text { Sample of } \\
\text { Monthly } \\
\text { Exclusions }\end{array}$ & $\begin{array}{c}\text { Total } \\
\text { Exclusions }\end{array}$ \\
Medical practice & 35 & 2,883 \\
Chiropractic practice & 21 & 1,290 \\
Psychology practice & 8 & 322 \\
Podiatry practice & 3 & 347 \\
Osteopathic practice & 2 & 237 \\
Optometry practice & 1 & 96 \\
Total & $\mathbf{7 0}$ & $\mathbf{5 , 1 7 5}$ \\
\hline
\end{tabular}

Coding Policy of 1996; the goal of HCFA to reduce improper payment rate to $5 \%$ or lower by fiscal year 2002 , from 8\% during fiscal year 1999; and President Clinton's proposal for fiscal year 2001 budget, with a multitude of initiatives to fight Medicare waste, fraud, and abuse, not only indicate the importance of regulatory influence, but also are influencing physician practices.

In the past, physicians followed a simple format characterized by an acronym, SOAP, which stands for subjective, objective, assessment, and plan. This was later expanded, presumably to meet the criteria of HCFA's evaluation and management services, to SOAPER to also include education and return instructions. Other variations of the same theme include SOAPIE, which stands for subjective, objective, assessment, plan, intervention and evaluation; and SNOCAMP, which stands for subjective, nature of presenting problem, counseling, assessment, medical decision making and plan. However, due to the complicated nature of the documentation guidelines proposed by HCFA, SOAP and SOAPER no longer meet the criteria in most cases. Other variations are as complicated as HCFA guidelines. The HCFA and American Medical Association, as well as other speciality societies, continue to struggle with differing opinions, and contentiously argue in favor of and against the various components of evaluation and management guidelines.

The most important aspect of billing and coding for evaluation and management services includes appropriate documentation of the level of service by documentation of history, which includes chief complaint, history of present 
Table 3. Sanctions of medical providers

\begin{tabular}{lcc}
\hline Sanction Type & $\begin{array}{c}\text { Sample of } \\
\text { Monthly } \\
\text { Exclusions }\end{array}$ & $\begin{array}{c}\text { Total } \\
\text { Exclusions }\end{array}$ \\
\hline $\begin{array}{l}\text { License revocation or } \\
\text { suspension }\end{array}$ & 173 & 5,485 \\
$\begin{array}{l}\text { Program-related } \\
\text { conviction }\end{array}$ & 65 & 5.403 \\
$\begin{array}{l}\text { Patient abuse and } \\
\text { neglect }\end{array}$ & 42 & 2,258 \\
$\begin{array}{l}\text { Default on health } \\
\text { education loan }\end{array}$ & 23 & 2,010 \\
$\begin{array}{l}\text { Sanctioned individual- } \\
\text { owned entity }\end{array}$ & 6 & 620 \\
Total & $\mathbf{3 0 9}$ & $\mathbf{1 5 , 7 7 6}$ \\
\hline
\end{tabular}

illness, review of systems, and past, family, and social history; physical examination, which includes either single-system or multisystem examination; and complexity of decision making, which includes straightforward, low complexity, moderate complexity, or high complexity.

\section{Importance of Documentation}

The HCFA reported losses of $\$ 12.6$ billion in 1998, and $\$ 13.5$ billion in 1999 in improper billing and overpayments to providers. Around the same time, the Office of the Inspector General (OIG) released a report that showed a mas-

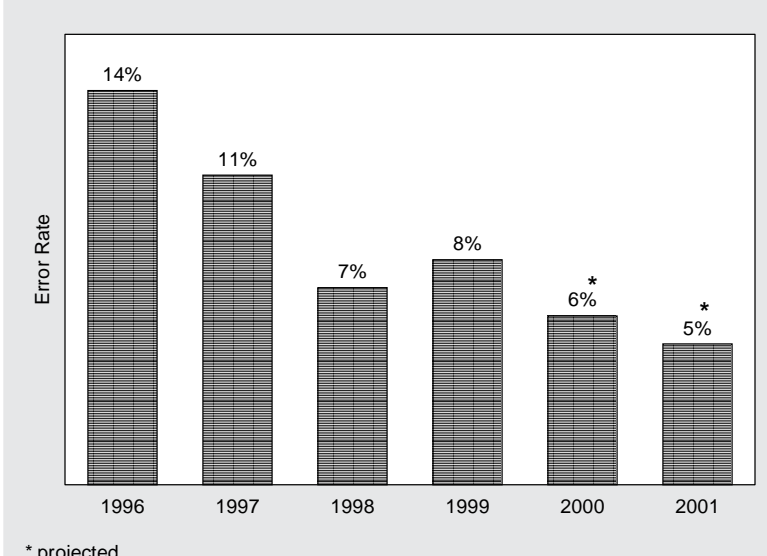

Fig 2. Medicare fee-for-service (FFS) error rates

sive war on health fraud. As shown in Fig. 1, 22\% of the total health-care overpayments were attributed to physician practices in 1999. The OIG also estimated that more than half of rehab payments in 1997-1998 fiscal year were improper: either medically not necessary, poorly documented, or not provided by licensed personnel. Along the same lines, HCFA also reported that it has recouped approximately $\$ 1.2$ billion in the first half of fiscal year 1999 from part B prepayment audits alone from ambulatory surgery centers, hospital outpatient departments, physician claims, and durable medical equipment, among others.

Interventional pain medicine is considered as a high-risk

Table 4. Various types of CPT codes utilized for evaluation and management services relevant to pain management

\begin{tabular}{|c|c|c|c|c|c|c|c|c|}
\hline $\begin{array}{c}\text { Level } \\
\text { of } \\
\text { Visit }\end{array}$ & $\begin{array}{l}\text { Type } \\
\text { of } \\
\text { Visit }\end{array}$ & $\begin{array}{c}\text { New } \\
\text { Patient } \\
\text { Office } \\
\text { Visit }\end{array}$ & $\begin{array}{c}\text { Established } \\
\text { Outpatient(s) }\end{array}$ & $\begin{array}{c}\text { Office } \\
\text { Consults } \\
\text { New or } \\
\text { Established } \\
\text { Patient(s) }\end{array}$ & $\begin{array}{c}\text { Initial } \\
\text { Inpatient New } \\
\text { or Established } \\
\text { Patient(s) }\end{array}$ & $\begin{array}{c}\text { Subsequent } \\
\text { Hospital Care }\end{array}$ & $\begin{array}{c}\text { Initial } \\
\text { Inpatient } \\
\text { Consult }\end{array}$ & $\begin{array}{c}\text { Follow-up } \\
\text { Inpatient } \\
\text { Consult }\end{array}$ \\
\hline 1 & $\begin{array}{l}\text { Problem } \\
\text { focused }\end{array}$ & 99201 & 99212 & 99241 & NA & NA & 99251 & NA \\
\hline 2 & $\begin{array}{l}\text { Expanded } \\
\text { problem focused }\end{array}$ & 99202 & 99213 & 99242 & NA & NA & 99252 & NA \\
\hline 3 & $\begin{array}{l}\text { Detailed/low } \\
\text { complexity }\end{array}$ & 99203 & 99214 & 99243 & 99221 & 99231 & 99253 & 99261 \\
\hline 4 & $\begin{array}{l}\text { Comprehensive/ } \\
\text { moderate } \\
\text { complexity }\end{array}$ & 99204 & 99215 & 99244 & 99222 & 99232 & 99254 & 99262 \\
\hline 5 & $\begin{array}{l}\text { Comprehensive/ } \\
\text { high complexity }\end{array}$ & 99205 & NA & 99245 & 99223 & 99233 & 99255 & 99263 \\
\hline
\end{tabular}


Table 5. Utilization for year 1998 for all new patients and speciality practices of anesthesiology, physiatry, and neurology

\begin{tabular}{|c|c|c|c|c|c|c|c|l|}
\hline \multirow{2}{*}{$\begin{array}{c}\text { CPT } \\
\text { Evaluation } \\
\text { Code }\end{array}$} & \multicolumn{2}{|c|}{$\begin{array}{c}\text { Total Visits by Category } \\
\text { for All Specialeties }\end{array}$} & \multicolumn{2}{c|}{$\begin{array}{c}\text { Visits for } \\
\text { Anesthesiology }\end{array}$} & \multicolumn{2}{c|}{$\begin{array}{c}\text { Visits for } \\
\text { Physiatry }\end{array}$} & \multicolumn{2}{c|}{ Visits for Neurology } \\
\cline { 2 - 9 } & No. of visits & Percent & No. of visits & Percent & Visits & Percent & Visits & Percent \\
\hline 99201 & 725,953 & $6 \%$ & 11,360 & $13 \%$ & 2,357 & $3 \%$ & 1,147 & $1 \%$ \\
\hline 99202 & $2,880,808$ & $26 \%$ & 10,285 & $12 \%$ & 7,556 & $9 \%$ & 2,785 & $3 \%$ \\
\hline 99203 & $3,868,534$ & $34 \%$ & 31,406 & $35 \%$ & 27,286 & $32 \%$ & 12,817 & $14 \%$ \\
\hline 99204 & $2,568,730$ & $23 \%$ & 23,073 & $26 \%$ & 29,703 & $35 \%$ & 34,626 & $37 \%$ \\
\hline 99205 & $1,251,461$ & $11 \%$ & 12,942 & $14 \%$ & 18,282 & $21 \%$ & 42,681 & $45 \%$ \\
\hline Total & $11,295,486$ & $100 \%$ & 89,066 & $100 \%$ & 85,364 & $100 \%$ & 94,056 & $100 \%$ \\
\hline
\end{tabular}

Source: HCFA Speciality Utilization File 1998

area next only to psychiatry and podiatry. Interventional pain medicine generally is a high-profile, high-volume, high-dollar practice that also includes physical therapy and psychological services. Thus, the consequences of incomplete or inaccurate coding, as shown in Table 1, are disastrous not only for medicine in general, but specifically for interventional pain medicine practices (8-10). This is confirmed by the large number of exclusions and sanctions of medical providers each month, with total exclusions amounting to 5,175 and total sanctions of medical providers amounting to 15,776 in 1999 (Tables 2 and 3). The HCFA also stated that its goal is to reduce the improper payment rate to $5 \%$ or lower by fiscal year
2002, from $8 \%$ in fiscal year 1999 (Fig. 2). In addition, HCFA intends to reduce the fee-for-service rate to $6 \%$ by October 2000. The HCFA, as well as President Clinton, has proposed multiple initiatives to fight Medicare waste, fraud, and abuse (11).

\section{Impact on Physician Practices}

In a recent survey by the Association of Medical Physicians and Surgeons, physicians expressed their concerns that the stepped-up threats of prosecution of doctors and government red tape may make it harder for Medicare beneficiaries to find doctors to treat them (11). According to

Table 6. Utilization for year 1998 for all established patients and speciality practices of anesthesiology, physiatry, and neurology

\begin{tabular}{|c|c|c|c|c|c|c|c|c|}
\hline \multirow{2}{*}{$\begin{array}{c}\text { CPT } \\
\text { Evaluation } \\
\text { Code }\end{array}$} & \multicolumn{2}{|c|}{$\begin{array}{l}\text { Total Visits by Category } \\
\text { for All Specialeties }\end{array}$} & \multicolumn{2}{|c|}{$\begin{array}{c}\text { Visits for } \\
\text { Anesthesiology }\end{array}$} & \multicolumn{2}{|c|}{$\begin{array}{l}\text { Visits for } \\
\text { Physiatry }\end{array}$} & \multicolumn{2}{|c|}{ Visits for Neurology } \\
\hline & No. of visits & Percent & No. of visits & Percent & Visits & Percent & Visits & Percent \\
\hline 99211 & $8,609,050$ & $5 \%$ & 35,478 & $6 \%$ & 27,319 & $4 \%$ & 35,698 & $1 \%$ \\
\hline 99212 & $29,884,479$ & $18 \%$ & 166,124 & $29 \%$ & 121,944 & $19 \%$ & 217,643 & $8 \%$ \\
\hline 99213 & $86,124,315$ & $52 \%$ & 243,592 & $42 \%$ & 306,568 & $47 \%$ & $1,073,467$ & $42 \%$ \\
\hline 99214 & $34,128,560$ & $21 \%$ & 107,740 & $19 \%$ & 159,242 & $25 \%$ & 990,981 & $39 \%$ \\
\hline 99215 & $6,263,370$ & $4 \%$ & 22,952 & $4 \%$ & 31,595 & $5 \%$ & 249,526 & $10 \%$ \\
\hline Total & $165,009,774$ & $100 \%$ & 575,886 & $100 \%$ & 646,668 & $100 \%$ & $2,567,315$ & $100 \%$ \\
\hline
\end{tabular}

Source: HCFA Speciality Utilization File 1998 
Table 7. Utilization for year 1998, for all new and established patient office consultations, and speciality practices of anesthesiology, physiatry, and neurology

\begin{tabular}{|c|c|c|c|c|c|c|c|c|}
\hline \multirow{2}{*}{$\begin{array}{c}\text { CPT } \\
\text { Evaluation } \\
\text { Code }\end{array}$} & \multicolumn{2}{|c|}{ All Specialeties } & \multicolumn{2}{c|}{ Anesthesiology } & \multicolumn{2}{c|}{ Physiatry } & \multicolumn{3}{c|}{ Neurology } \\
\cline { 2 - 10 } & Number & Percent & Number & Percent & Number & Percent & Number & Percent \\
\hline 99241 & 559,453 & $6 \%$ & 18,976 & $12 \%$ & 10,151 & $9 \%$ & 9,521 & $1 \%$ \\
\hline 99242 & $1,411,327$ & $15 \%$ & 29,995 & $20 \%$ & 15,789 & $13 \%$ & 24,054 & $4 \%$ \\
\hline 99243 & $2,785,759$ & $30 \%$ & 40,796 & $27 \%$ & 37,912 & $32 \%$ & 89,242 & $13 \%$ \\
\hline 99244 & $3,093,116$ & $34 \%$ & 42,096 & $28 \%$ & 37,525 & $32 \%$ & 366,032 & $52 \%$ \\
\hline 99245 & $1,417,606$ & $15 \%$ & 20,652 & $13 \%$ & 15,974 & $14 \%$ & 209,772 & $30 \%$ \\
\hline Total & $9,267,261$ & $100 \%$ & 152,515 & $100 \%$ & 117,351 & $100 \%$ & 698,621 & $100 \%$ \\
\hline
\end{tabular}

Source: HCFA Speciality Utilization File 1998

this survey, $82 \%$ of physicians reported an increased fear of prosecution or investigation during the past three years; and $71 \%$ reported making changes in their practice to avoid the threat of prosecution, including restricting services. It is interesting to note that $66 \%$ of physicians plan to retire from patient care at an earlier age than they would have considered 5 years ago, $23 \%$ of the responding physicians have stopped accepting Medicare patients, and 34\% of the responding physicians reported having difficulty finding physicians who would accept their Medicare patients for consultations.

Physicians' fear of being prosecuted is not paranoia. The federal government is seeking as much as \$37 million from

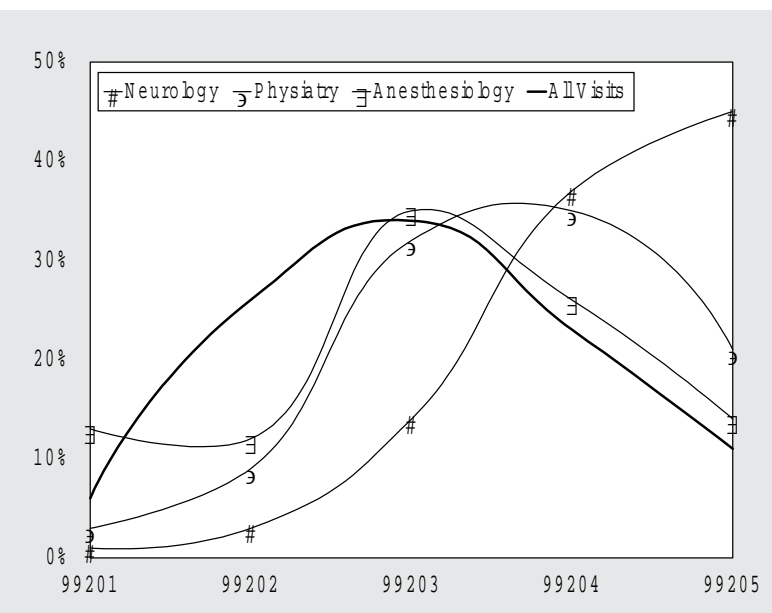

Fig 3. Comparison of 1998 E/M utilization data - new patient office visits a physician for allegedly overbilling by upcoding, surprisingly in general practice (12). This physician's charges are allegedly out of the norm for her specialty, with her coding consisting of only $7 \%$ of level 3 , but $49 \%$ of level 4 , and $26 \%$ of level 5 (12). Similarly, an anesthesia group settled for $\$ 3.2$ million for insufficient supervision; an ophthalmologist settled for $\$ 8.5$ million for upcoding; and an emergency physician group settled for $\$ 15$ million for upcoding. In addition, the OIG in its 1999 work plan is targeting $600,000+$ physicians in practice.

\section{EVALUATION AND MANAGEMENT SERVICES}

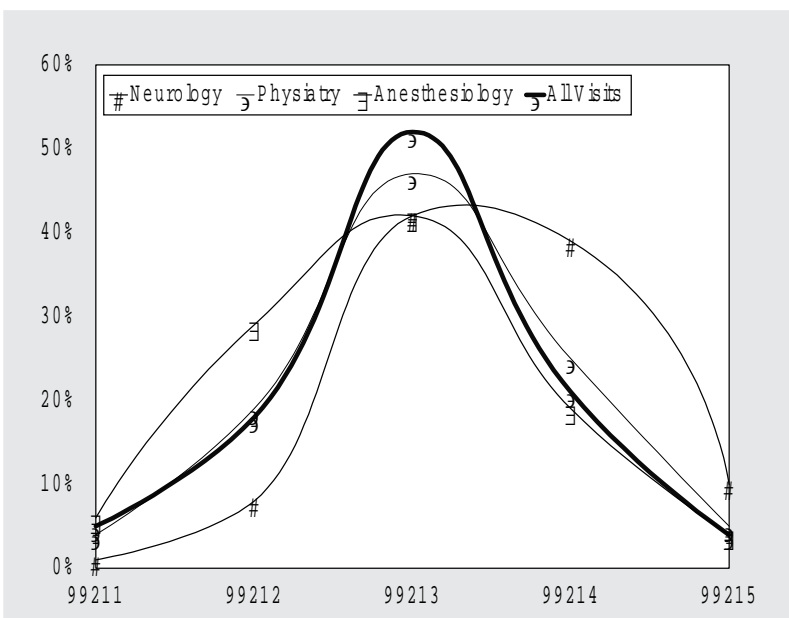

Fig 4. Comparison of 1998 E/M utilization data - established patient office visits 
Table 8. Utilization of initial inpatient and subsequent hospital care visits for 1998, for all specialties; and specialty practices of anesthesiology, physiatry, and neurology

\begin{tabular}{|c|c|c|c|c|c|c|c|c|}
\hline \multirow{2}{*}{$\begin{array}{c}\text { CPT } \\
\text { Evaluation } \\
\text { Code }\end{array}$} & \multicolumn{2}{|c|}{$\begin{array}{l}\text { Total Visits by Category } \\
\text { for All Specialties }\end{array}$} & \multicolumn{2}{|c|}{$\begin{array}{c}\text { Visits for } \\
\text { Anesthesiology }\end{array}$} & \multicolumn{2}{|c|}{ Visits for Physiatry } & \multicolumn{2}{|c|}{ Visits for Neurology } \\
\hline & No. of visits & Percent & No. of visits & Percent & No. of visits & Percent & No. of visits & Percent \\
\hline $\begin{array}{l}99221 \\
\text { Initial }\end{array}$ & 601,318 & $1 \%$ & 3,492 & $2 \%$ & 23,885 & $1 \%$ & 9,011 & $1 \%$ \\
\hline \begin{tabular}{|l|}
99222 \\
Initial \\
\end{tabular} & $3,063,172$ & $4 \%$ & 3,999 & $2 \%$ & 87,865 & $2 \%$ & 34,672 & $1 \%$ \\
\hline $\begin{array}{l}99223 \\
\text { Initial }\end{array}$ & $4,506,558$ & $6 \%$ & 3,305 & $2 \%$ & 114,661 & $3 \%$ & 67,879 & $3 \%$ \\
\hline \begin{tabular}{|l|}
99231 \\
Subsequent \\
\end{tabular} & $23,359,861$ & $30 \%$ & 98,555 & $52 \%$ & $2,108,548$ & $58 \%$ & 985,160 & $39 \%$ \\
\hline \begin{tabular}{|l}
99232 \\
Subsequent \\
\end{tabular} & $34,269,766$ & $43 \%$ & 51,154 & $27 \%$ & $1,050,522$ & $30 \%$ & $1,064,203$ & $42 \%$ \\
\hline \begin{tabular}{|l|}
99233 \\
Subsequent \\
\end{tabular} & $12,312,919$ & $16 \%$ & 27,668 & $15 \%$ & 228,667 & $6 \%$ & 357,958 & $14 \%$ \\
\hline Total & $78,113,594$ & $100 \%$ & 188,173 & $100 \%$ & $3,614,148$ & $100 \%$ & $2,518,883$ & $100 \%$ \\
\hline
\end{tabular}

\section{Utilization Statistics}

Table 4 shows CPT codes for all types of visits relevant to pain management. These do not include critical care and emergency department visits. As shown in Table 5, all Medicare new-patient visits total 11, 295,486. Of these, 89,066 were by anesthesiologists; 85,364 were by physiatrists; and 94,056 were by neurologists. While the majority of anesthesiology visits may represent pain management, only a portion of physiatry and neurology visits constitute pain management. Similarly, as shown in Table 6 , all established patient visits amounted to $165,009,774$.

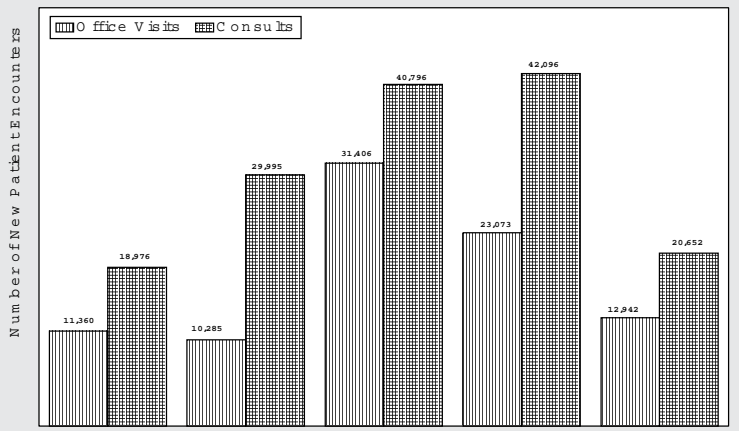

Fig 5. Comparison utilization of evaluation codes by anesthesiologists in 1998 for various levels of services - new patients office visit vs. consultation
Of these, 575,886 were by anesthesiologists; 646,668 were by physiatrists; and 2, 567,315 were by neurologists for 1998. Office consultations exceeded a total of $9,000,000$; of which 152,515 were by anesthesiologists; 117,351 were by physiatrists; and 698,621 were by neurologists (Table 7). There were also a significant number of visits involving initial inpatient visits, and hospital consults. These are illustrated in Tables 8 and 9; however, these do not include nursing home visits and emergency department visits.

As shown in Fig. 3, a bell-shaped curve is obtained for all new patient visits. This was also true for anesthesiology and physiatry, whereas neurology failed to conform to a bell-shaped curve. This may be due to neurologists' seeing many patients with neurological disorders requiring higher levels of services. Similarly, as shown in Fig. 4, established patient visits conform to a bell-shaped curve when plotted for all specialties combined. In addition, a bell-shaped curve was also obtained for all specialties including anesthesiology, physiatry, and neurology.

Fig. 5 shows the rate of utilization of new-office patient visits versus office consultations in anesthesiology practices, which mostly constitutes pain management. Such differentiation emphasizing pain management was not feasible for either physiatry or neurology. The OIG believes that evaluation and management coding is the area of greatest exposure for physicians and medical practices. The documentation criteria for correct coding of these standard office visits are extensive. Several of the OIG risk 
Table 9. Utilization of hospital consults, initial, and follow-up for 1998, for all specialties; and specialty practices of anesthesiology, physiatry, and neurology

\begin{tabular}{|c|c|c|c|c|c|c|c|c|}
\hline \multirow[t]{2}{*}{$\begin{array}{c}\text { CPT } \\
\text { Evaluation } \\
\text { Code }\end{array}$} & \multicolumn{2}{|c|}{$\begin{array}{l}\text { Total Visits by } \\
\text { Category for all } \\
\text { Specialties }\end{array}$} & \multicolumn{2}{|c|}{$\begin{array}{l}\text { Visits for } \\
\text { Anes thesiology }\end{array}$} & \multicolumn{2}{|c|}{ Visits for Physiatry } & \multicolumn{2}{|c|}{ Visits for Neurology } \\
\hline & No. of visits & Percent & No. of visits & Percent & No. of visits & Percent & No. of visits & Percent \\
\hline $\begin{array}{l}99251 \\
\text { Initial }\end{array}$ & 486,523 & $1 \%$ & 14,899 & $19 \%$ & 13,650 & $3 \%$ & 6,099 & $1 \%$ \\
\hline $\begin{array}{l}99252 \\
\text { Initial }\end{array}$ & $1,042,865$ & $2 \%$ & 13,215 & $17 \%$ & 39,396 & $9 \%$ & 18,793 & $2 \%$ \\
\hline $\begin{array}{l}99253 \\
\text { Initial }\end{array}$ & $2,408,096$ & $5 \%$ & 14,801 & $19 \%$ & 134,747 & $31 \%$ & 103,974 & $9 \%$ \\
\hline $\begin{array}{l}99254 \\
\text { Initial } \\
\end{array}$ & $37,584,494$ & $80 \%$ & 9,241 & $12 \%$ & 124,335 & $29 \%$ & 430,748 & $38 \%$ \\
\hline $\begin{array}{l}99255 \\
\text { Initial }\end{array}$ & $2,089,373$ & $4 \%$ & 4,482 & $6 \%$ & 32,040 & $7 \%$ & 247,292 & $22 \%$ \\
\hline $\begin{array}{l}99261 \\
\text { Follow-up }\end{array}$ & 945,740 & $2 \%$ & 11,564 & $14 \%$ & 34,608 & $8 \%$ & 74,400 & $7 \%$ \\
\hline $\begin{array}{l}99262 \\
\text { Follow-up }\end{array}$ & $1,700,095$ & $4 \%$ & 8,730 & $11 \%$ & 42,161 & $10 \%$ & 161,816 & $14 \%$ \\
\hline $\begin{array}{l}99263 \\
\text { Follow-up }\end{array}$ & 857,666 & $2 \%$ & 2,101 & $2 \%$ & 13,964 & $3 \%$ & 82,009 & $7 \%$ \\
\hline Total & $47,114,852$ & $100 \%$ & 79,033 & $100 \%$ & 434,901 & $100 \%$ & $1,125,131$ & $100 \%$ \\
\hline
\end{tabular}

areas fall into the coding category. They include upcoding (billing at a higher code than what is documented in the medical record); billing for services rendered by nonphysicians (the nurse visit office code, 99211, is one of the most misused codes, according to the OIG); medical necessity (in many cases physician notes will not clearly state the medical necessity for the services rendered); and misrepresenting diagnosis to justify services (assigning a diagnosis to meet a specific code level is a way in which some physicians have "gamed" the Medicare system in the past). Physicians recognize the difficulty involved in good documentation and correct coding. However, it has been noted that undercoding is as much a problem as overcoding. Undercoding puts the practice at risk of losing money following defensive coding. In addition, undercoding also sends up a red flag at HCFA, just like overcoding. Investigators assume that if the physician is incorrectly coding in one direction, it is quite possible that the same physician may be coding incorrectly in another direction by upcoding others. With more than 132,000 pages of complex federal regulations covering the Medicare program, the IRS, with 17,000 pages of regulations, appears much simpler and friendlier. However, unfortunately, physicians do not have to deal with the IRS on a daily basis, whereas they have to deal with Medicare in an active practice. The OIG claims that improper documentation, and lack of medical necessity account for $70 \%$ of bad claims.
The HCFA announced that it plans to adopt a policy that will address undercoding by physicians who bill Medicare, along with upcoding. The HCFA has proposed definitions for minor, intermediate, and major error levels by the percent of errors discovered in an audit. Fewer than $5 \%$ errors constitutes the lowest level of concern, which could invite the carrier to remove the practice from edit sweeps. However, if billing error rate tops $36 \%$, it is an indication of impending trouble (13). The error rates now range from below $5 \%$ to above $51 \%$ of claims. Undercoding is defined as a claim that has supporting documentation to justify a higher level of service than was billed. The HCFA's

\section{Table 10. Functions and requirements of} patient's medical record

\begin{tabular}{|c|c|c|}
\hline Clinical Record & Business Record & $\begin{array}{c}\text { HCFA's } \\
\text { Requirements }\end{array}$ \\
\hline $\begin{array}{c}\text { Indicates quality of } \\
\text { care }\end{array}$ & $\begin{array}{c}\text { Supports insurance } \\
\text { billing }\end{array}$ & $\begin{array}{c}\text { Supports "medical } \\
\text { necessity" }\end{array}$ \\
\hline $\begin{array}{c}\text { Promotes continuity } \\
\text { of care among } \\
\text { physicians }\end{array}$ & $\begin{array}{c}\text { Facilitates claim } \\
\text { review }\end{array}$ & Complete \\
\hline $\begin{array}{c}\text { Provides clinical data } \\
\text { for research }\end{array}$ & $\begin{array}{c}\text { Reduces audit } \\
\text { exposure }\end{array}$ & Legible \\
\hline $\begin{array}{c}\text { Provides clinical data } \\
\text { for education }\end{array}$ & $\begin{array}{c}\text { Reduces professional } \\
\text { liability exposure }\end{array}$ & Signed \\
\hline
\end{tabular}


attention to undercoding is apparently in response to bitter complaints of physicians, who claim that carriers are supposed to pay correctly, whether claims are upcoded or undercoded (13). Detection of undercoding during a prepayment audit by carriers will result in the sending of information to the practice that it can appeal the claim to get paid for the higher CPT code. If undercoding is detected during a postpayment audit, carriers will "net out" the payments; however, this policy appears to be more harmful than beneficial to providers, as it may trigger increased levels of audit activity.

\section{Medical Necessity}

Medical necessity requires appropriate diagnosis and coding by ICD-9-CM to justify services rendered and indicate the severity of the patient's condition (14). The Balanced Budget Act (HR 2015, Section 4317) requires all physicians to provide the diagnostic information for all Medicare/Medicaid patients starting from January 1, 1998 (10). Further, failure to comply with this regulation can result in prosecution. Physicians should code by listing the ICD-9$\mathrm{CM}$ diagnostic codes shown in the medical record to be chiefly responsible for the services provided. Coding should be to the highest degree of certainty for each encounter. Coding also should correlate with multiple com- ponents of the patient's medical record, including initial evaluation or follow-up visits, and billing statement. One "silver lining" for interventional pain practices is that chronic conditions treated on an ongoing basis may be reported as many times as the patient receives care for the condition. If proper diagnosis is not established, codes that describe symptoms and signs, as opposed to the diagnosis, are acceptable for reporting purposes until the diagnosis is confirmed.

\section{Medical Record}

A medical record is a document with confidential information that functions as a clinical record, as well as a business record (Table 10). A properly executed medical record facilitates and provides information with regards to:

Why did the patient present for care?

What was done?

- Where were the services rendered?

- When is the patient to return or what is the plan of action?

- Will there be follow-up tests or procedures ordered?

Table 11. HCFA guidelines differentiating features of consultation and a referral visit

\begin{tabular}{|c|c|c|}
\hline & Consultation & Referral Visit \\
\hline 1. Problem & Suspected & Known \\
\hline 2. Request language & $\begin{array}{l}\text { "Please examine patient and provide me with your } \\
\text { opinion and recommendation on his/her condition." }\end{array}$ & $\begin{array}{l}\text { Patient is referred for treatment or management of } \\
\text { his/her condition. }\end{array}$ \\
\hline 3. Request & $\begin{array}{l}\text { Written request for opinion or advice received from } \\
\text { attending physician, including the specific reason } \\
\text { the consultation is requested. }\end{array}$ & $\begin{array}{l}\text { Patient appointment made for the purpose of providing } \\
\text { treatment or management or other diagnostic or } \\
\text { therapeutic services. }\end{array}$ \\
\hline 4. Report language & $\begin{array}{l}\text { "I was asked to see Mr. Jones in consultation by } \\
\text { Dr. Johnson." }\end{array}$ & $\begin{array}{l}\text { "Mr. Jones was seen following a referral from Dr. } \\
\text { Johnson." }\end{array}$ \\
\hline 5. Patient care & $\begin{array}{l}\text { Only opinion or advice sought. Subsequent to the } \\
\text { opinion, treatment may be initiated in the same } \\
\text { encounter. }\end{array}$ & $\begin{array}{l}\text { Transfer of total patient care for management of the } \\
\text { specified condition. }\end{array}$ \\
\hline 6. Treatment & Undetermined course . & Prescribed and known course. \\
\hline 7. Correspondence & Written opinion returned to attending physician. & $\begin{array}{l}\text { No further communication (or limited contact) with } \\
\text { referring physician is required. }\end{array}$ \\
\hline 8. Diagnosis & Final diagnosis is probably unknown. & $\begin{array}{l}\text { Final diagnosis is typically known at the time of } \\
\text { referral. }\end{array}$ \\
\hline 9. Follow-up & $\begin{array}{l}\text { Patient advised to follow-up with attending } \\
\text { physician. }\end{array}$ & $\begin{array}{l}\text { Patient advised to return for additional discussion, } \\
\text { testing, treatment, or continuation of treatment and } \\
\text { management. }\end{array}$ \\
\hline 10. Further follow-up & $\begin{array}{l}\text { Confirmatory or follow-up consultation or } \\
\text { established patient based on specific situation. }\end{array}$ & Already established patient for 3 years. \\
\hline
\end{tabular}




\section{Levels of Service}

Evaluation and management services in pain management are office outpatient services and hospital inpatient services (Table 4). Five levels of services are available for office outpatients, four levels for established office outpatients (comprehensive/high complexity not available), and five levels for consultations and new patient visits that include:

Level 1 - Problem focused,

Level 2 - Expanded problem focused,

Level 3 - Detailed/low complexity,

Level 4 - Comprehensive/moderate complexity, and

Level 5-Comprehensive/high complexity.

Hospital services include initial inpatient, either new or established patients; subsequent hospital care; initial inpatient consultations; and follow-up inpatient consultations (Table 4). Initial inpatient and subsequent hospital care is divided into three levels encompassing:

Level 1 - Detailed/low complexity,

Level 2 - Comprehensive/moderate complexity, and

Level 3 - Comprehensive/high complexity.

Initial and follow-up inpatient consultations, however, differ in that initial inpatient consultations are at five levels similar to new patient consultations but follow-up inpatient consultations are only at three levels.

The descriptors for the levels of evaluation and management services recognize seven components, of which three components are considered crucial in defining the levels of evaluation and management services in interventional pain management. Three crucial components are:

- History,

- Physical examination, and

- Medical decision making.

Other components include:

- Counseling,

- Coordination of care,

- Nature of presenting problem, and

$\checkmark \quad$ Time.

Because the level of evaluation in management service is dependent on two or three components, performance and documentation of one component at the highest level does not necessarily mean that the encounter in its entirety qualifies for the highest level of evaluation and management service.

If counseling or coordination of care is provided as the predominant service constituting more than $50 \%$ of the time by the physician, then time may be considered the key or controlling factor to qualify for a particular level of evaluation and management service.

\section{Consult Versus Visit}

Interpretation of the guidelines for consultations versus visits and billing for these services, along with the level of service, are contentious issues. Recent guidelines by HCFA have clarified some of the issues involved in the confusion with regards to this issue (Table 11). The guidelines suggest that any time a physician sees a patient at the request of another physician, the visit may be a consultation (1). However, there are four considerations for the visit to qualify for a consultation.

- First, the requesting physician must be seeking the advice of the consulting physician, not transferring care.

- Second, there must be documentation in the patient's record of the request for a consultation. Third, the level of service must be documented in the patient's record.

Fourth and last, there must be documentation that the consulting physician has communicated his or her findings to the requesting physician in writing.

Table 11 shows the differences between a consultation and visit. The CPT and HCFA guidelines have always stated that a physician may order laboratory tests and/or institute treatment at the time of a consultation. Hence, if an interventional medicine physician is asked to see a patient with back pain, either in the hospital or in the office, the interventional pain specialist may institute treatment and the visit may still be a consultation; however, it becomes a visit if the referring physician arranges for the receiving physician to take over part or all of the care prior to the receiving physician is 000seeing the patient. Another misunderstood issue with regards to consultation is that if the receiving physician assumes part or all of the care of the patient, then subsequent visits must not be coded as a consultation but as subsequent outpatient or hospital care. This is somewhat confused with initial visits 
in some cases. Follow-up consultations would be appropriate only when there is a period of time between visits. For example, if an interventional pain physician saw a patient in consultation, made recommendations and signed off and then would be asked to see the patient because the treatment did not work, that might be follow-up consultation. One of the major requirements of consultation is that of documentation in the patient's record that consultation in fact was requested. This can be accomplished by a letter from the requesting physician asking for the consultation, or a consultation request slip followed by documentation by the consulting physician with something similar to: "I was asked to see this patient in consultation by Dr. Smith." Documentation that findings of the consulting physician were communicated in writing to the requesting physician is also crucial. This is also accomplished by sending the requesting physician a copy of the patient record, and a thank-you letter. Unfortunately, recently published guidelines require that it be in writing, contradicting the earlier guidelines where communication by telephone was sufficient. Coding for a large number of consultations raises red flags for HCFA medical directors who are monitoring each physician's coding profile. Thus, abnormal coding profiles are likely to bring on audits; and, therefore, interventional pain medicine specialists must weigh the increased revenue from a consultation versus the possible consequences of audit, which may include not only evaluation and management services, but may also be extended to any other area of the practice.

\section{PROCESS OF EVALUATION}

\section{History}

History constitutes one of the three crucial components of evaluation and management, the other two being physical examination and medical decision making. All patients, whether new or established, seen in the office or in the hospital setting, for visits or consultation, require documentation of history based on level of service. The history includes:

Chief complaint,
History of present illness,
Past, family, and/or social history.

The extent of history obtained and documented is dependent upon the clinical judgment of the physician and the nature of the presenting problem of the patient. Nevertheless, the required documentation is progressively detailed and complex, with brief and problem pertinent for problem focused and extended problem focused to extended and complete for detailed comprehensive and comprehensive/ complex services.

Chief Complaint: The chief complaint is a concise statement describing the symptom, problem, condition, diagnosis, physician-recommended return, or other factor that is the reason for the encounter, usually stated in the patient's words. This should be clearly documented in the medical record.

The chief complaint should always be the first thing in initial evaluation, history and physical, progress note, and consultation report. Examples of chief complaint or statement include:

Low back pain,
Pain in the neck,
Headache,
Inability to move shoulder
Pain for the past week,
Pain in the spine,
Management of back pain,
Back that still hurts,
Follow-up for back pain,
Head that still hurts,
Inability to walk,
Reason for appointment: evaluation and
management, and
Here for injection therapy.

However, chief statements such as

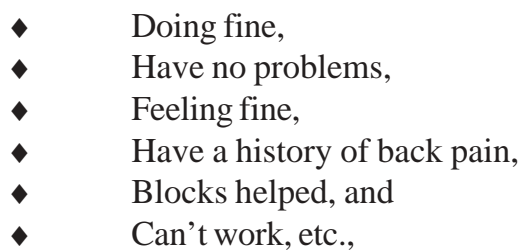

will not suffice. It is critical that the chief complaint establishes medical necessity.

However, if medical necessity of the visit is not established with the chief complaint, this can be established in the history of present illness by a statement to explain the purpose of the patient's visit, such as:

- Mr. Jones is here for further evaluation and management with injection therapy, or Mr. Jones is here for further evaluation and pre- 
scription refills.

History of Present Illness: History of present illness is a chronological description of the development of the patient's present illness from the first sign and/or symptom or from the previous encounter to the present. It includes the following elements:

- Location - describing the area of the body;

- Quality - sensation or pattern that will be satisfied by the McGill Pain Questionnaire, either short form or long form;

- Severity - satisfied by pain-rating scale, either visual analog scale or numerical scale describing the level of pain;

- Duration - symptom duration from onset to the present encounter;

- Timing - description of the pain pattern: continuous, intermittent, in the evening or afternoon, etc.;

- Context-specific circumstances, conditions, and activities surrounding the present condition;

- Modifying factors - measures taken to relieve symptoms or discomfort, such as physical therapy, surgery, injection therapy, drug therapy, etc., and results with these measures; and

Associated signs and symptoms - such as numbness, weakness, blurred vision, disturbed sleep pattern, or difficulty with activities of daily living, etc.

Brief and extended history of present illness is distinguished by the amount of detail needed to accurately characterize the clinical problem(s) $(8,10)$. Brief history of present illness requires documentation of one to three elements of the present illness, whereas extended history of present illness requires documentation of at least four elements of the history of present illness or the status of at least three chronic or inactive conditions. Further, a brief history of present illness suffices for problem-focused and expanded-problem-focused visits, whereas extended with at least four elements or status of three inactive or chronic conditions is required for detailed comprehensive and comprehensive complex levels of services $(8,10)$. Examples of brief history of present illness with one to three elements include:

- Severe low back pain with radiation into leg,

- Severe neck pain with headache and radiation to both upper extremities, and

- Throbbing headache for 2 months.
Examples of extended history of present illness with four elements or status of three chronic or inactive elements may be achieved with careful articulation of patient symptomatology with one or more conditions; for example, intermittent, severe low back pain with radiation into left lower extremity, associated with occasional numbness, tingling, and weakness, since 1978, which started following a fall from the roof.

Review of Systems: Review of systems is an inventory of body systems obtained through a series of questions seeking to identify signs and/or symptoms that the patient may be experiencing or has experienced $(8,10)$. Guidelines recognize the following 14 systems for purposes of review of systems, also known as medical review. These systems include:

$\begin{array}{ll} & \text { Constitutional; } \\ & \text { Eyes; } \\ & \text { Ears, nose, mouth, throat; } \\ & \text { Cardiovascular; } \\ & \text { Respiratory; } \\ & \text { Gastrointestinal; } \\ & \text { Genitourinary; } \\ & \text { Musculoskeletal; } \\ & \text { Integumentary (skin and/or breast); } \\ & \text { Neurological; } \\ & \text { Psychiatric; } \\ & \text { Endocrine; } \\ & \text { Hematologic/lymphatic; and } \\ & \text { Allergy/immunologic. }\end{array}$

Review of systems is described at three levels, which include problem pertinent, extended, and complete. Problem pertinent involves the documentation of the patient's pertinent responses, both positive as well as negative, for the system related to the problem. In contrast, an extended review of systems includes positive and pertinent negatives for two to nine systems, as listed above. For complete review of systems, at least 10 systems must be reviewed and documented; however, while those systems with positive or pertinent negative responses must be individually documented, a notation indicating that the remaining systems are negative is acceptable. In the absence of such a notation, at least 10 systems must be individually documented.

Review of systems is not required for problem-focused visits, either for new patients or established patients. For the expanded problem-focused level, problem-pertinent review of system with positives and negatives is required. 
However, for detailed, ie, level 3, for new patients as well as established patients, extended review of systems with positive and pertinent negatives for two to nine systems is required. For comprehensive levels, complete review of systems with at least 10 systems is required.

Information for review of systems is obtained through a series of questions, either by a questionnaire or through recording by ancillary staff. However, physicians should document that the information was reviewed. Hence, there must be notation supplementing or confirming the information recorded by others. If the physician is unable to obtain a history from the patient or other source, the record should describe the patient's condition or other circumstance that precludes obtaining a history.

Review of systems may be listed as separate elements of the history, or they may be included in the description of the history of present illness.

A review of history obtained during an earlier encounter does not need to be rerecorded if there is evidence that the physician reviewed and updated the previous information. This may occur when a physician updates his or her own record or when many physicians use a common record in an institutional setting or group practice. The review and update may be documented by:

Describing any new information or noting that there has been no change in the information; and Noting the date and location of the earlier review of system documentation.

Appropriate levels of system reviews can be met by using a comprehensive questionnaire enabling the patient or the ancillary staff to record all the systems; thus, during the documentation pertinent positives and negatives and all positives may be recorded, followed by a statement that all other systems were negative.

Past, Family, and/or Social History: The past, family, and/ or social history consists of:

- A review of the past history of the patient including past experiences, illnesses, operations, injuries, and treatments;

Family history, including a review of medical events in the patient's family, hereditary diseases, and other factors; and

- Social history appropriate for age reflecting past

Table 12. Illustration of HCFA requirments for various levels of service

\begin{tabular}{|c|c|c|c|c|c|c|c|c|}
\hline \multirow[b]{2}{*}{ Type of Visit } & \multicolumn{5}{|c|}{ Documentation of History } & \multicolumn{2}{|c|}{ Physical Examination } & \multirow{2}{*}{$\begin{array}{c}\text { Complexity } \\
\text { of } \\
\text { Decision } \\
\text { Making }\end{array}$} \\
\hline & $\begin{array}{c}\text { CPT } \\
\text { Codes }\end{array}$ & $\begin{array}{c}\text { Chief } \\
\text { Complaint }\end{array}$ & $\begin{array}{c}\text { History of } \\
\text { Present Illness } \\
\text { (HPI) }\end{array}$ & $\begin{array}{c}\text { Review of } \\
\text { Systems (ROS) }\end{array}$ & $\begin{array}{c}\text { Past, Family, } \\
\text { and Social } \\
\text { History (PFSH) }\end{array}$ & $\begin{array}{c}\text { General } \\
\text { Multisystem }\end{array}$ & Single System & \\
\hline $\begin{array}{l}\text { Problem-Focus- } \\
\text { ed } \\
\text { Level } 1\end{array}$ & $\begin{array}{l}99201 \\
99241 \\
99212\end{array}$ & 3 & $\begin{array}{l}\text { Brief } \\
\text { One to three } \\
\text { Elements }\end{array}$ & N/A & N/A & $\begin{array}{l}\text { Limited to affected } \\
\text { body areas } \\
\text { one to five elements }\end{array}$ & $\begin{array}{l}\text { Limited to affected } \\
\text { body areas } \\
\text { one to five elements }\end{array}$ & $\begin{array}{l}\text { Straight-for- } \\
\text { ward }\end{array}$ \\
\hline $\begin{array}{l}\text { Expanded-Prob- } \\
\text { lem Focused } \\
\text { Level } 2\end{array}$ & $\begin{array}{l}99202 \\
99242 \\
99243\end{array}$ & 3 & $\begin{array}{l}\text { Brief } \\
\text { One to three } \\
\text { Elements }\end{array}$ & $\begin{array}{c}\text { Problem Pertinent } \\
\text { Positives and } \\
\text { Negatives }\end{array}$ & N/A & $\begin{array}{l}\text { Limited to } \\
\text { symptomatic or } \\
\text { related systems } \\
\text { six elements }\end{array}$ & $\begin{array}{l}\text { Limited to symptomatic } \\
\text { or related systems } \\
\text { six elements }\end{array}$ & $\begin{array}{l}\text { Straight-for- } \\
\text { ward }\end{array}$ \\
\hline $\begin{array}{l}\text { Detailed } \\
\text { Level } 3\end{array}$ & $\begin{array}{l}99203 \\
99243 \\
99214\end{array}$ & 3 & $\begin{array}{c}\text { Extended } \\
\text { At least four } \\
\text { elements or status } \\
\text { of three chronic or } \\
\text { inactive conditions }\end{array}$ & $\begin{array}{l}\text { Extended } \\
\text { Positive and } \\
\text { Pertinent } \\
\text { negatives } \\
\text { two to nine } \\
\text { systems }\end{array}$ & $\begin{array}{c}\text { Pertinent } \\
\text { To problems } \\
\text { identified in HPI }\end{array}$ & $\begin{array}{l}\text { Extended } \\
\text { At least two from } \\
\text { each systems or } \\
\text { twelve in two or } \\
\text { more systems }\end{array}$ & $\begin{array}{l}\text { Extended examination } \\
\text { of symptomatic and } \\
\text { related systems } \\
\text { at least twelve elements }\end{array}$ & $\begin{array}{c}\text { Low } \\
\text { Complexity }\end{array}$ \\
\hline $\begin{array}{l}\text { Comprehensive } \\
\text { Level } 4\end{array}$ & $\begin{array}{l}99204 \\
99244 \\
99215\end{array}$ & 3 & $\begin{array}{c}\text { Extended } \\
\text { At least four } \\
\text { elements or status } \\
\text { of three chronic or } \\
\text { inactive conditions }\end{array}$ & $\begin{array}{l}\text { Complete } \\
\text { At least ten } \\
\text { systems }\end{array}$ & $\begin{array}{c}\text { Complete } \\
\text { At least one } \\
\text { specific HPI from } \\
\text { three of three } \\
\text { history areas }\end{array}$ & $\begin{array}{c}\text { Comprehensive } \\
\text { At least two elements } \\
\text { from nine systems } \\
\text { eighteen elements }\end{array}$ & $\begin{array}{l}\text { Complete Every } \\
\text { element in each box } \\
\text { with a shaded border } \\
\text { and at least one } \\
\text { element in each box } \\
\text { with unshaded border }\end{array}$ & $\begin{array}{c}\text { Moderate } \\
\text { Complexity }\end{array}$ \\
\hline $\begin{array}{l}\text { Comprehensive } \\
\text { Complex } \\
\text { Level } 5\end{array}$ & $\begin{array}{l}99205 \\
99245\end{array}$ & 3 & $\begin{array}{l}\text { Extended } \\
\text { At least four } \\
\text { elements or status } \\
\text { of three chronic or } \\
\text { inactive conditions }\end{array}$ & $\begin{array}{l}\text { Complete } \\
\text { At least ten } \\
\text { systems }\end{array}$ & $\begin{array}{c}\text { Complete } \\
\text { At least one } \\
\text { specific HPI from } \\
\text { three of three } \\
\text { history areas }\end{array}$ & $\begin{array}{c}\text { Comprehensive } \\
\text { At least two elements } \\
\text { from nine systems } \\
\text { eighteen elements }\end{array}$ & $\begin{array}{l}\text { Complete Every } \\
\text { element in each box } \\
\text { with a shaded border } \\
\text { and at least one } \\
\text { element in each box } \\
\text { with unshaded border }\end{array}$ & $\begin{array}{c}\text { High } \\
\text { Complexity }\end{array}$ \\
\hline
\end{tabular}


and current activities.

There are two levels of past, family, and/or social history: pertinent to problems identified in history of present illness; and complete, which includes at least one specific history of present illness item from three of the three history areas. A problem-focused or expanded problem-focused visit does not require past, family, and/or social history; however, a detailed visit requires at least one specific item from one of three areas of the history to be pertinent, in contrast to comprehensive, which requires complete past, family, and/or social history with at least one specific history of present illness from three of the three history areas for new patients and at least two specific items from three history areas for established patients.

Past, family, and/or social history may be listed as a separate element of the history, or it may be included in the description of the history of the present illness; it may be recorded by ancillary staff or on a questionnaire or a form completed by the patient. To document that a physician, in fact, reviewed the information, there must be notation supplementing or confirming the information recorded by others.

If the physician is unable to obtain a history from the patient or other source, the record should describe the patient's condition or other circumstance which precludes obtaining a history.

Past, family, and/or social history obtained during an earlier encounter does not need to be rerecorded if there is evidence that the physician reviewed and updated the previous information. This may occur when a physician updates his or her own record or when many physicians use a common record in an institutional setting or group practice. The review and update may be documented by describing any new information or noting there has been no change in the information and noting the date and location of the earlier past, family, and/or social history.

Past history in interventional pain medicine includes history of past pain problems, ranging from headaches to numbness or tingling in the feet, motor vehicle injuries, Workman's Compensation injuries, or nonoccupational injuries; history of headache, neck pain, upper-extremity pain, pain in the upper, or mid back or chest wall, pain in the lower back or lower extremities, and pain in joints; and disorders such as arthritis, fibromyalgia, or systemic lupus erythematosus.
Family history includes history of pain problems in the family such as low back pain, neck pain, mid back or upper back pain, chest wall pain, extremity pain, headaches, migraine, arthritis, fibromyalgia, multiple sclerosis, and systemic lupus erythematosus; drug dependency, alcoholism, or drug abuse; and psychological disorders such as depression, anxiety, schizophrenia, and suicidal tendencies, etc.

Social history includes environmental information, education, marital status, children, habits, hobbies, and occupational history, whenever available.

An example of documentation of past history is as follows: Mr. Jones suffered with low back pain in the past, and sustained a work-related injury in 1995, which resulted in neck pain. He was involved in a motor vehicle injury in 1984. He denied any history of any other pain problems, injuries, fibromyalgia, or arthritis.

An example of documentation of family history includes that the history was positive for migraine, arthritis, and low back pain in the family; but that it was negative for fibromyalgia, systemic lupus erythematosus, alcoholism, drug dependency, depression, schizophrenia, and epilepsy.

Social history may be documented as follows: lives in any town, is a high school graduate, is married with three children, works as a carpenter, has smoked three packs of cigarettes since 1978, does not drink alcohol, and plays golf for recreation. All of these may be separated into various sections indicating environment, occupation, habits, and hobbies.

\section{Physical Examination}

Various levels of evaluation and management services are based on four types of examination. However, the type of examination is dependent upon the nature of the presenting problem(s) and clinical judgment of the physician.

Problem focused - It is a limited examination of the affected body area or organ system(s), including examination of one to five bullet-point elements from a single-system examination such as musculoskeletal.

Expanded problem focused - This examination involves:

- A limited examination of the affected 
Table 13. Comparison of musculoskeletal and neurological - single-system examinations for interventional pain practice, with general multisystem - physical examination

\begin{tabular}{|c|c|c|c|}
\hline \multirow{2}{*}{ Systems } & \multirow{2}{*}{ Multisystem } & \multicolumn{2}{|c|}{ Single System } \\
\hline & & Musculoskeletal & Neurologic \\
\hline Constitutional & Two elements & Two elements & Two elements \\
\hline Musculoskeletal & Six elements & Five elements & Three elements \\
\hline Neurological & Three elements & Two elements & Sixteen elements \\
\hline Cardiovascular & Seven elements & One element (Peripheral) & Three elements \\
\hline Chest/breasts & Two elements & ----- & ----- \\
\hline $\begin{array}{l}\text { Ears, nose, mouth and } \\
\text { throat }\end{array}$ & Six elements & ----- & ----- \\
\hline Eyes & Three elements & 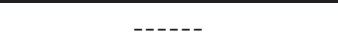 & One element (Ophthalmoscopy) \\
\hline Genitourinary & $\begin{array}{c}\text { Four elements - male } \\
\text { Seven elements - female }\end{array}$ & ----- & ----- \\
\hline Gastrointestinal & Five elements & ----- & ----- \\
\hline Lymphatic & Four elements & One element & ----- \\
\hline Psychiatric & Four elements & Two elements & $\begin{array}{ll}---- \\
--1\end{array}$ \\
\hline Respiratory & Four elements & ----- & ----- \\
\hline Skin & Two elements & One element & ----- \\
\hline $\begin{array}{l}\text { body ar } \\
\text { Any oth } \\
\text { areas or } \\
\text { tation o } \\
\text { element } \\
\text { gan syst }\end{array}$ & $\begin{array}{l}\text { organ system, and } \\
\text { mptomatic or related body } \\
\text { an systems, with documen- } \\
\text { east six of the bullet-point } \\
\text { m one of the } 10 \text { single-or- } \\
\text { xaminations. }\end{array}$ & $\begin{array}{ll} & \text { Eyes; } \\
& \text { Genitourinary } \\
& \text { Genitourinary } \\
& \text { Hematologic } \\
& \text { Psychiatric; } \\
& \text { Respiratory; } \\
& \text { Skin. }\end{array}$ & $\begin{array}{l}\text {-female; } \\
\text { - male; } \\
\text { lymphatic/immunologic; } \\
\text { and }\end{array}$ \\
\hline
\end{tabular}

- Detailed - This is an extended examination of the affected body area(s) or organ system(s) and any other symptomatic or related body area(s) or organ system(s), with documentation of at least 12 bullet points or elements from one of the 10 singlesystem examinations.

- Comprehensive - This is a general multisystem examination, a complete examination of a single organ system and other symptomatic or related areas or organ systems, with documentation of all elements identified by a bullet.

Various types of examinations include either general multisystem examination or single-organ-system examination. Single-organ-system examinations include examination of any of the 10 organ systems:

- Musculoskeletal;

- Neurological;

- Cardiovascular;

- Ears, nose, mouth, and throat;
A general multisystem examination or a single-organ-system examination may be performed by any physician, regardless of the speciality. The type of the examination, however, whether it is general multisystem or single-organ-system and its content(s) is selected by the examining or consulting physician and based upon clinical judgment, the patient's history, and the nature of the presenting problem or problems(s).

In interventional pain management, the following types of examinations are suitable.

\section{- General multisystem examination, \\ - A single-organ system examination consisting of musculoskeletal or neurological systems.}

However, other systems including psychiatric may be utilized if necessary. The content in documentation requirements for each type and level of examination is summarized and described in Tables 12 and 13. Some of the important 
aspects of the evaluation and management and physical examination are as follows:

- Performance and documentation of one component at the highest level does not necessarily mean that the encounter in its entirety qualifies for the highest level of service.

- The three key components are history, examination, and complexity of medical decision making. The chief complaint, review of systems, and past, family, or social history may be listed as separate elements of history; or they may be included in the description of the history of the present illness.

- The review of systems and the past, family, and social history may be recorded by ancillary staff or on a form completed by the patient. However, the physician must document that the information was reviewed by making a notation supplementing or confirming the information recorded by others. If the history is unobtainable, either from the patient or other source, the record should describe the patient's condition or other circumstance, which precludes obtaining a history.

- "Abnormal" - A notation without elaboration is insufficient. Specific abnormal and relevant findings of the examination of the affected or symptomatic body area or areas or organ system or systems should be documented.

- Abnormal or unexpected findings of the examination of any asymptomatic body area or areas or organ system or organ systems should be described.

- "Negative" or "normal" is sufficient to document normal findings related to unaffected area or ar-

Table 14. Progression of elements required for each level of medical decision making

\begin{tabular}{|l|l|l|l|}
\hline $\begin{array}{l}\text { Type of } \\
\text { Mecision } \\
\text { Making }\end{array}$ & $\begin{array}{l}\text { Number of } \\
\text { Diagnoses or } \\
\text { Management } \\
\text { Options }\end{array}$ & $\begin{array}{l}\text { Amount and/or } \\
\text { Complexity of } \\
\text { Data To Be } \\
\text { Reviewed }\end{array}$ & $\begin{array}{l}\text { Risk of } \\
\text { Complications } \\
\text { and/or } \\
\text { Morbidity or } \\
\text { Mortality }\end{array}$ \\
\hline $\begin{array}{l}\text { Straightforw- } \\
\text { ard }\end{array}$ & Minimal & Minimal or none & Minimal \\
\hline $\begin{array}{l}\text { Low } \\
\text { complexity }\end{array}$ & Limited & Limited & Low \\
\hline $\begin{array}{l}\text { Moderate } \\
\text { complexity }\end{array}$ & Multiple & Moderate & Moderate \\
\hline $\begin{array}{l}\text { High } \\
\text { complexity }\end{array}$ & Extensive & Extensive & High \\
\hline
\end{tabular}

eas of asymptomatic organ system (s).

- Documentation for each element must satisfy any numeric requirements.

\section{General Multisystem Examinations}

General multisystem examination(s), although they appear simpler and may fit universal needs, are somewhat complex. To qualify for a given level of multisystem examination, the documentation should include:

- Problem-focused examination - Should include performance and documentation of one to five elements in one or more organ system(s) or body $\operatorname{area}(\mathrm{s})$;

- Expanded problem focused - Should include performance and documentation of at least six elements in one or more organ system(s) or body $\operatorname{area}(\mathrm{s})$;

- Detailed examination - Should include at least six organ systems or body areas for each system/ area selected; performance and documentation of at least two elements is expected; however, alternatively, a detailed examination may include performance and documentation of at least 12 elements in two or more organ systems or body areas;

- Comprehensive - Comprehensive examinations should include at least nine organ systems or body areas; for each system/area selected, all elements of the examination should be performed unless specific directions limit the content of the examination; for each area or system, documentation of at least two elements identified by a bullet is expected.

Even though criteria can be met by examining each area or system and documenting at least two elements, the difficulties with general multisystem examination include:

- Ophthalmoscopic examination of the optic discs and posterior segments,

- Otoscopic examination of the external auditory canals and tympanic membranes,

- Inspection and palpation of breasts, and

- Examination of the genitourinary system.

However, comprehensive examination can be met by examination of only 9 out of 12 organ systems or body areas.

Single-Organ-System Examination(s) 
Single-organ-system examination(s) include an examination of any of the 12 systems. However, variations among these examinations in the organ systems and body areas reflect differing emphasis among specialties. To qualify for a given level of single-organ-system examination, the following content and documentation requirements should be met.

- Problem-focused - This examination should include performance and documentation of one to five elements.

- Expanded problem-focused - This examination should include performance and documentation of at least six elements.

- Detailed examination - Examinations other than the eye and psychiatric examination should include performance and documentation of at least 12 elements.

- $\quad$ Eye and psychiatric examination - Examinations should include the performance and documentation of at least nine elements.

- Comprehensive - This examination should include documentation of all elements.

MConstitutional Examination: Musculoskeletal examination includes the musculoskeletal system as the single primary organ system and multiple other systems. Various systems capable of contributing a number of elements to th Cavdlastismilam usculoskeletal examination, single system, are as follows:

- Two elements:
Measurement of any three of the seven
vital signs, and
General appearance of the patient.
- One element:

Neurologic/psychiatric tion of the peripheral/vascular system.

- One element:

Palpation of lymph nodes.

- One element:

- Inspection and palpation of the skin in subcutaneous tissue.

Musculoskeletal
Test coordination;
Deep tendon reflexes;
Sensation;
Assessment of mental status -orienta-
tion to time, place, and person; and
Mood and effect.

- Five elements:

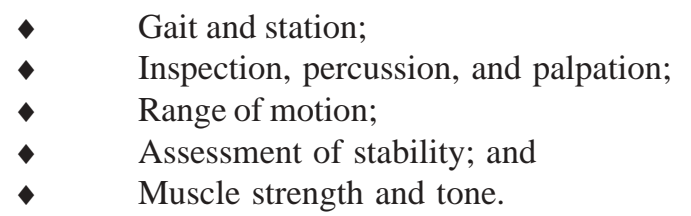

Thus, the musculoskeletal system has, potentially, a total of 15 elements; 12 from shaded, bordered systems; and 3 from unshaded bordered systems. The problem-focused examination may be satisfied by examining only the musculoskeletal system. However, expanded problem-focused examination requires at least six elements that will require complete examination of the musculoskeletal system, with five elements and at least one other system with one element, either constitutional, neurological, lymphatic, cardiac, or skin. Detailed examination requires 12 elements, which will require examination of multiple systems to meet the criteria of 12 elements. This can be met by five elements from the musculoskeletal system; five from the neurologic and psychiatric examination; and an additional two from either the constitutional, skin, cardiovascular, or lymphatic systems. Comprehensive requires complete examination or performance of all elements and documentation of every element in each box with a shaded border, and at least one element in each box with an unshaded border, which means examination and documentation of two elements from the constitutional, five elements from the musculoskeletal system examination, one element from the skin ex Constitutional five elements from the neurologic/psychiatric examination; and at least one element from the peripheral vascular and lymphatic, which is all elements.

\section{Eyes}

Neurologic Examination: Specific areas in neurological ex Gaxinditionsiouldard:

$$
\begin{aligned}
& \text { - Two elements: } \\
& \text { Three of the seven vital signs, and } \\
& \text { General appearance. } \\
& \text { Exhthalmoscopic examination. } \\
& \text { - Three elements: } \\
& \text { Euscultation of the heart, and } \\
& \text { Examination of the peripheral/vascular } \\
& \text { System. } \\
& \text { Examination of gait and station, } \\
& \text { Muscle strength in upper and lower ex- } \\
& \text { tremities, and }
\end{aligned}
$$




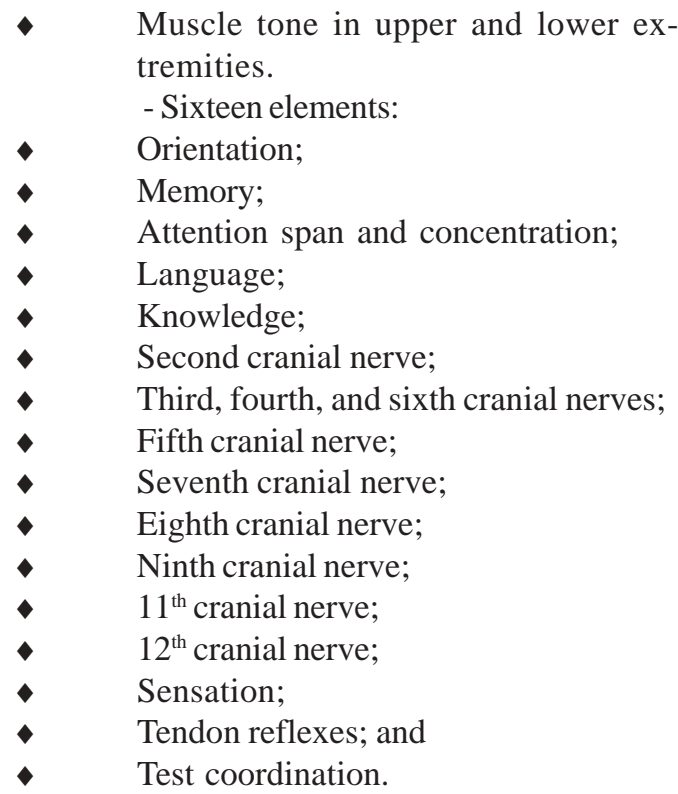

Hence, problem focused, which requires one to five elements, and expanded problem focused, which requires six elements, are easily met by examination of the neurological system. Similarly, a detailed examination (which requires 12 elements) can also be met by examination of the neurological system alone. However, a comprehensive examination should include all elements from systems with shaded borders, namely constitutional, musculoskeletal, neurological, and eyes; and one element from the cardiovascular, totaling 23 elements. The major disadvantage of the neurological examination in chronic pain involves ophthalmoscopic examination of the optic discs and posterior segments, and detailed examination of all cranial nerves. If ophthalmoscopic examination is not performed, the physical examination will not meet the criteria for comprehensive.

Differences between musculoskeletal and neurological examination, along with similarities in comparison to general multisystem examination, are illustrated in Table 13.

\section{Medical Decision Making}

Documentation of the complexity of medical decision making involves four types of medical decision making to accommodate all levels of evaluation and management services. Medical decision making refers to the complexity of establishing a diagnosis and/or selecting a management option as measured by three components, including: (1)diagnosis/management options, with number of possible diagnoses and/or the number of management options; (2) review of records/investigations, with number and/or com- plexity of medical records, diagnostic tests, and other information that must be obtained, reviewed, and analyzed; and (3) risk(s) of significant complications, morbidity and mortality, as well as comorbidities associated with the patient's presenting problem(s), the diagnostic procedure(s), and/or the possible management options.

The four types of medical decision-making options include:

Straightforward,
Low complexity,
Moderate complexity, and
High complexity.

Table 14 shows the progression of elements required for each level of medical decision making. To qualify for a given type of decision making, at least two of the three elements in the table must be either met or exceeded.

\section{Diagnosis or Management Options}

The number of possible diagnoses and/or the number of management options that must be considered is based on the number and types of problems addressed during the encounter, the complexity of establishing a diagnosis, and management decisions that are made by the physician. The number and type of diagnostic tests employed may be an indicator of the number of possible diagnoses. Problems that are improving or resolving are less complex than those that are worsening or failing to change as expected. The need for further consultations or advice from others is another indicator of complexity of diagnostic or management problems.

Following are some important aspects in documenting diagnosis and/or management options.

- For each encounter, an assessment, clinical impression, or diagnosis should be documented. It may be explicitly stated or implied in documented decisions regarding management plans and/or further evaluation.

For a presenting problem with an established diagnosis, the records should reflect whether the problem is:

- Improved, well-controlled, resolving, or resolved;

- Inadequately controlled, worsening, or failing to change as expected

For a presenting problem without an established 
diagnosis, the assessment or clinical impression may be stated in the form of differential diagnosis or as a possible, probable, or rule-out diagnosis.

- The initiation of, or changes in, treatment should be documented.

- The treatment includes a wide range of mangement options, including patient instructions, nursing instructions, therapies, and medications.

- If referrals are made, consultations are requested or advice is sought, they must be indicated on the record with details as to whom or where the referral or consultation is made.

\section{Review of Records/Investigations}

The nature, amount, and complexity of data to be reviewed are based on the types of diagnostic testing ordered or reviewed. A decision to obtain and review old medical records and/or obtain history from sources other than the patient increases the amount and complexity of data to be reviewed.

Discussion of contradictory or unexpected test results with the physician who performed or interpreted the tests is an indication of the complexity of the data being reviewed. It is not uncommon for an interventional pain physician to personally review the images to supplement the reports of other physicians or include an independent report. The following documentation is important:

- Whenever a diagnostic service, test, or procedure is ordered, planned, scheduled, or performed at the time of the encounter, the type of service should be documented.

- The review of investigations including radiology and/or other diagnostic tests should be documented. A simple notation such as, "MRI showed disc herniation at L5/S1 level," or "MRI was grossly within normal limits" is acceptable. Alternatively, the review may be documented by initialing and dating the report containing the test results.

- Documentation should be made with regards to the decision to obtain old records or additional history from the family or other sources to supplement that obtained from the patient.

- Documentation of relevant findings from the review of the old records, additional history from the family, or other sources is important; however, if there is no relevant information beyond that already obtained, that fact should be documented.

A notation of old records reviewed or additional history obtained from the family without elaboration of the facts of what was reviewed and the result of the review is insufficient.

The results of discussion of radiology or other diagnostic tests with either the radiologist or neurologist or any other physician who performed or interpreted the study should be documented. The independent interpretation of imaging studies should be documented.

\section{Risks}

The risks of significant complications, morbidity, and/or mortality are based on the risks associated with:

- The presenting problem(s),

- The diagnostic procedure(s), and

- Possible management options.

Some important aspects of the risks in interventional pain management are:

- Co-morbidity, underlying disease, or other factors that increase the complexity of medical decision making by increasing the risk of complications, morbidity, and/or mortality should be documented.

- Planned or scheduled invasive diagnostic or therapeutic procedures or surgical procedures at the time of the encounter should be documented, with the type of procedure.

- If an invasive diagnostic, therapeutic or surgical procedure is performed at the time of the encounter, the specific procedure should be documented. - If the patient is referred for an emergency, invasive diagnostic, therapeutic procedure, or surgical intervention, such referrals should be documented.

Table 9 shows some salient aspects in the determination of risks, whether minimal, low, moderate, or high. However, the determination of risks is complex and not readily quantifiable, and is also variable with each specialty. In addition, the assessment of risk of the presenting problems is based on the risks related to the disease process anticipated between the immediate and the next encounter. The assessment of risk of selecting diagnostic procedures and management options is also based on the risk during and 
immediately following any procedures or treatments. The highest level of risk in any one category of the three described determines the overall risks.

\section{Counseling and/or Coordination of Care}

If either counseling and/or coordination of care dominates the physician/patient and/or family encounter (faceto-face time in the office or other outpatient setting exceeding $50 \%$ of the time), time is considered the key or controlling factor to qualify for a particular level of evaluation and management service. However, if the physician elects to report the level of service based on counseling and coordination of care, the total length of time of the encounter (face-to-face or floor time, as appropriate) should be documented and the records should describe the counseling and/or activities.

\section{PROPOSED NEW GUIDELINES}

The new guidelines proposed in 1998 will soon go for pilot testing; hence, it is expected that if all goes well, these guidelines will be implemented in late 2000 or early 2001. Some of the advantages of the new guidelines are as follows:

- They are presented in a shorter document.

- They include new history and examination definitions and a relaxed set of documentation guidelines that may remove some of the "three of the three" coding requirements for the history and documentation of new patient encounters.

- The history of present illness definitions includes: the status of one or two "chronic or inactive conditions," brief (one to three of eight); the status of at least three "chronic or inactive conditions" extended (four plus of eight).

- The review-of-systems definitions for extended and complete history have been significantly reduced.

- The definition for a complete past, family, and/ or social history has been modified, with at least one item from any two of the three history areas instead of three of the three for new patients.

- The definition for examinations has been simplified by:

- $\quad$ Eliminating confusing instructions (example: "Perform all elements, shaded and unshaded boxes"),

- Enhancing clinical flexibility by elimi- nating rigid distinctions between general multisystem versus single-system examinations, and

- Increasing the level of freedom for physicians.

Record keeping has been simplified, as new guidelines state that any type of record format is acceptable, including simple check lists to indicate.

\section{CONCLUSION}

Evaluation and management services are part and parcel of the practice of interventional pain management. Consequences of inappropriate coding and insufficient documentation to support charges billed to Medicare include, not only penalties, but also exclusion from the Medicare program, and, finally, prison terms. Understanding appropriate documentation issues of medical necessity and rules and regulations governing evaluation and management coding is extremely crucial. Appropriate documentation not only will meet the criteria for billing and coding at an appropriate level, but also will result in higher reimbursement, providing a safety net to avoid fraud and abuse. This not only complies with the regulations, but also improves patient care. The new regulations, which may be released for implementation in late 2000 or early 2001, will not only clarify a multitude of issues but will also make it easier for physicians, not only to document appropriate level of service, but also to do this with less confusion and fear.

\section{REFERENCES}

1. Haralson R. Consultation coding tips. NASS News 2000; XIV(II):1-6.

2. Masquelier E, Plaghki L, Gizisart J et al. Tutorial 42: History taking - Examination and management of low back pain. Pain Digest 1999; 9:258-275.

3. Portenoy RK, Kanner RM. Definition and assessment of pain. In Portenoy RK, Kanner RM (eds). Pain Management: Theory and Practice. Philadelphia, FA Davis Company, 1996, pp 3-18.

4. Donohoe CD. Targeted history and physical examination. In Waldman SD, Winnie AP (eds). Interventional Pain Management. Philadelphia, W.B. Saunders Company, 1996, pp 73-84.

5. Wall PD, Melzack R (eds). Textbook of Pain. New York, Churchill Livingstone, 1994.

6. McPeak LA. Physiatric history and examination. In Braddom RL (ed): Physical Medicine and Rehabilitation. Philadelphia, W.B. Saunders Co., 1996; pp 3-42.

7. Turk DC, Melzack R. (eds). Handbook of Clinical 
Assessment of Pain. New York, Guilford Press, 1992.

8. Evaluation and Management Services. Anesthesia Answer Book 1999. Rockville, MD pp 13501-13594.

9. Manchikanti L. Appropriate documentation, billing and coding of interventional pain procedures. Pain Physician 2000; 3:218-236.

10. Manchikanti L. The role of evaluation and management services in pain management. Pain Physician 1999; 2:10-32.
11. Butler L. Clinton budget boosts efforts to combat Medicare fraud. American Med News 2000; 43:1, 34, 35.

12. Klein SA. Feds try new talk in charging doctors with upcoding. American Med News 2000; 43:5-6.

13. Part 'B' News 2000; 14(7):

14. International Classification of Diseases, Ninth Revision, Clinical Modification, ICD-9-CM. Reston, St. Anthony Publishing, 1998. 